This is a pre-copyedited, author-produced PDF of an article accepted for publication in British Journal of Social Work following peer review. The version of record Helm D \& Roesch-Marsh A (2017) The ecology of judgement: a model for understanding and improving social work judgements, British Journal of Social Work, 47 (5), pp. 1361-1376 is available online at: https://doi.org/10.1093/bjsw/bcw091 


\title{
The ecology of judgement: a model for understanding and improving social work judgements
}

\begin{abstract}
Professional judgement is viewed as a crucial yet complex aspect of social work practice. Significant factors in judgement are understood to include individual psychological and emotional processes, interpersonal communication and the relationship between social work as a profession and society. Each contributory factor must be described and understood clearly in its own right and there is also a need to describe and understand the ways in which these different elements interact as parts of a complex system. We propose an ecological model of judgement that facilitates consideration of the complex non-linear interactions between multiple components forming a system or 'ecology' of judgement. Originating in the concepts of ecological rationality and systems thinking this paper proposes the ecology of judgement as a clear and logical model which practitioners and organisations can use to support and promote critical reflexive judgement in practice.
\end{abstract}

\section{Keywords}

Child protection Child safeguarding Decision-making

\section{Introduction}

Current models of judgement in social practice tend to emphasise a focus individual who is expected to conform to the notion of the rational actor; the individual who considers all available information and makes judgements which aim to maximise utility value. Serious Case Reviews (SCR) are held when neglect or abuse lead to child death or significant injury and these reviews have been a prominent source of learning for social work practice (e.g. Laming 2009, Hawthorne and Wilson 2009). However SCR reports still tend to focus on individual error without fuller consideration of the wider working environment which contributed to and influenced the judgement (Fish et al. 2008). Links between the individual and the broader environment are mediated through the role of supervision. In this model, reflective supervision is seen as a means of guarding against errors of judgement (Munro 2010) but seldom is consideration given to the way in which individual practitioners form judgements in the context of broader organisational, societal and political pressures. A model is required which can map and describe the relational and interactional aspects of judgement and can consider the influences between systems and individuals in professional judgement and decision making.

With the introduction of ecological frameworks for assessment (DoH 2000) practitioners were observed to provide an incomplete analysis of the child's needs and experiences because they failed to analyse the impact of socio/environmental factors on needs and caregiving (Jack and Gill 2003). When considering social work judgements, we would argue that this "missing side" exists in current thinking about how to promote and support effective 
judgment in social work practice. In addition to the skills and knowledge required of individual social workers, we also need to think holistically and ecologically about what the social worker needs from those supporting them and how the broader professional context impacts upon their judgement space.

\section{An ecological model of judgement and decision making}

Systems (or ecological) approaches have been developed in many areas of research and practice as a means of understanding how different systems operate, interact and influence each other. Many of the concepts related to systems approaches have been adopted by social work practitioners and social scientists (see for example (Pincus and Minahan 1973, Bronfenbrenner 1979, Byrne 1998, Forder 1976, Munro 2011, Bauman et al 2011, Stepney and Ford 2012) providing useful and familiar frameworks for analysis and intervention (e.g. DoH 2000, Scottish Executive 2005).

Particularly in England, government concerns about the quality of safeguarding judgements have lead to increasing and problematic levels of prescription (Munro 2010, 2011) predominated by a focus on individuals' values, skills and knowledge. This can lead to a methodological individualism (Weber 1978, Basu 2008) that denies the inherently contingent nature of professional judgement. Understanding and developing judgement and decision making in child welfare and protection requires a holistic model which provides a clear means of conceptualising and describing the complexity and interconnectedness of the factors which inform and influence such judgements.

Munro's systems-based analysis was a broad-ranging consideration of the entire system of child safeguarding. The Social Care Institute for Excellence (SCIE) (Fish et al. 2008) have used systems theory to consider learning from serious case reviews. In this paper, we use an ecological model in relation to a complex yet more distinctly defined area of practice: the process of sensemaking in assessment; also known as analysis and judgement. We explore the way in which micro-systems and meso-systems interconnect with the macro-system to form an ecology of judgement. We analyse key components of this ecology, using the model to identify practice tensions and promote debate about the efficacy of current and proposed actions to improve the quality of judgements in social work practice. Figure 1 takes the familiar 'child's world' triangle and reconceptualises it as the 'social worker's world': their ecology of judgement. This provides the theoretical model with a physical representation to help application in practice and, in this paper, we give consideration to each side of the transactional model before discussion the implications for practice. 


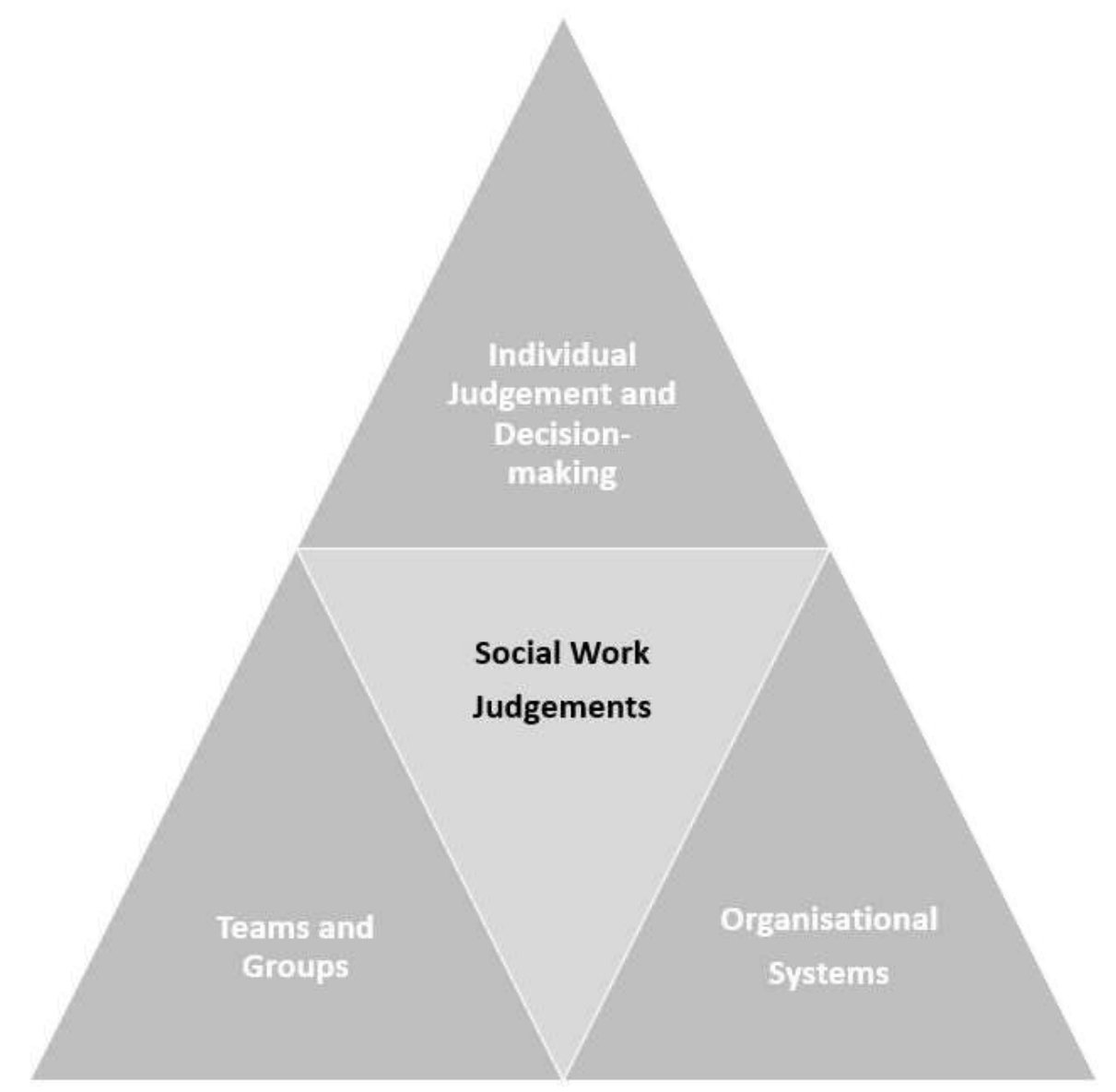

Figure 1: Ecology of judgement

\section{Individual judgement and decision making}

Social work requires practitioners to routinely make subjective decisions on the basis of contested, complex and often incomplete data and these are challenging conditions that place boundaries on the extent to which an ideal 'rational' judgement can be practiced (Hammond 1996, Baron 2008, Gambrill 2012). Attempts to achieve better rationality (such as evidence-based practice, application of theory and procedural conformity) arguably fail to acknowledge the inherently substantive nature of judgements in social work (Horwath 2006). Professional sense-making is indeed informed by theory, research and organisational structures but it is also shaped by context, culture and both personal and professional values and these are issues that are too frequently missing from dialogue about social work judgements (Taylor and White 2001).

Practitioners need to be able to use a range of cognitive approaches in judgement, incorporating and blending intuitive and analytical thinking. There is a growing understanding of deliberative (analytical) and non-deliberative (intuitive) thinking (Kahneman 2011). The information environment (e.g. the size, nature and form of data) determines the extent to which a person will employ these different systems in their judgement (Hammond 1996). Social 
work is a job that is heavily reliant on intuitive thinking (Van de Luitgaarden 2010) and practitioners therefore need to understand when this is appropriate and when a more rigorous and methodical approach is required for defensible decision-making. These different judgement styles can be taught and developed (Munro 2011) but this takes considerable time and expertise (Klein 1998). This higher order meta-cognition provides a critical appraisal not just of the information but the information environment itself (Eraut 2007). The nature and influence of the information environment on cognition is therefore of significance to a set of professionals who are required to be strongly analytical yet repeatedly make quick judgements under conditions of uncertainty.

Child safeguarding decisions are defined by high levels of uncertainty and low levels of consensus. Without omniscience, perfectly rational judgement is not possible (Simon 1955, Gigerenzer 2007) and practitioners are, in reality, faced with making 'good enough' or 'satisficing' (Simon 1955) judgements based on an incomplete consideration of data until an apparently 'good enough' solution is found. Many judgements in social work are value judgements and the drive for security and certainty in those making the judgements can lead to over-confidence and an unchallenged analysis of the situation (Munro 2008). Individual judgements are made in the context of an organisation whose own goals and priorities may be significant influences on the individual practitioner (Hughes and Wearing 2007). An ecological model provides a concrete and visual means of mapping those interacting factors which influence analysis and inform the threshold of 'good enough'.

Applying an ecological perspective is a powerful antidote to the predominating positivism inherent in technical-rational approaches as it openly acknowledges the situated and constructed nature of such judgements, thereby supporting a more rigorous and appraisal of the data. Secondly, an ecological model provides practitioners with a means of examining their own sense-making activity as part of a larger set of interacting systems. This person-in-situation analysis is useful as a sense of overwhelming or unrealistic responsibility is a key factor in burnout for workers (Morrison 2005) and attribution error (Munro 2008). Approaching this type of decision making with an ecological mindset can therefore support the individual worker to develop a more reflexive and multilayered analysis of the decision situation.

\section{Judgement and decision-making in teams and groups}

Much of the decision making in social work is done, formally or informally, in groups (White and Stancombe, 2003; White and Featherstone, 2005; Taylor and White, 2001; Gillingham and Humphreys, 2010; Forkby and Hojer, 2011; Roesch-Marsh, 2011; Roesch-Marsh, 2013; Smith, 2014). From informal chats at the photocopier, to structured multi-disciplinary group decision making fora such as Child Protection Case conferences, the complexity of decision making and the procedural context compels us to seek out the advice and support of others. Our ecological model of decision making, with its interest in the inter-connections between people, places and practices, explicitly recognises the importance of teams and groups. The model suggests that in order to improve social work judgment and decision making 
we must analyse the way that people work together in decision making groups and organisations.

The first step is conceptual. Do we recognise the crucial role that others play in the way we go about making decisions? As Atkinson (1995, p.52) points out:

Decision making itself is a collective organizational activity ... . 'decisions' may be subject to debate, negotiation and revision, based on talk within and between groups or teams of practitioners ... The silent inner dialogue of single-handed decision making, therefore, is by no means the whole story.

This process of formal and informal consultation, debate and negotiation within groups and teams is only one layer in the process of influence from group to individual and back again. As Forkby and Hojer (2011, p.166) argue, teams and groups within organisations also have a 'collective memory', defined as "an array of possible connections used in order to give meaning to and motivate actions in a certain situation", which may act as a guide for individuals in the decision making process, even when they are not consciously aware of its influence.

There is a small but growing body of empirical literature investigating the dynamics and outcomes of group decision making in social work (Kelly and Milner, 1996, 1999; Harlow, 2004; Harlow and Shardlow, 2006; Prince et al. 2005; Hitzler and Messmer, 2010; Roesch-Marsh, 201). These studies indicate that groups can be just as prone to errors in judgement as individuals. They also suggest that the task of group decision making in social work is a particularly complex one requiring an understanding of the aims and focus of the decision making group, confidence and a set of well developed "communicative competencies" (Hitzler and Messmer, 2010, p. 206) including the ability to communicate in a multi-disciplinary context (White and Featherstone 2005) and an understanding of children and families' experiences in group decision making (Thoburn et al., 1995; Corby et al., 1996; Hall and Slembrouk, 2001; Ghaffar et al. 2012, Miller and Fisher, 1992; Prince et al., 2005; Beckett et al. 2007).

The success of formal safeguarding decision making groups is often determined by the quality of chairing (Harlow 2004; Prince et al. 2005; Harlow and Shardlow 2006). The chair must be able to surface the relevant information and analysis from each group member, maintain a clear distinction between fact, observation, allegation and opinion and be able to help the group maintain its focus on the child and the child's timescales (Calder, 2003, Prince et al. 2005). This highlights the crucial role played by the chair as interface between individual judgements and group decision making in formal decision-making groups.

The ecological model is also useful in thinking about the value that different professionals bring to the decision making table. As we know from biological science, healthy ecosystems are characterised by species diversity, with each 
species making a unique and vital contribution to the whole. The challenge of the group decision making process is to make the most of the opportunity that having a diverse range of perspectives around the table provides (Harlow and Shardlow, 2006; Hitzler and Messmer, 2010). Gaps in membership or lack of participation from particular agencies may also indicate weaknesses at a local strategic level, highlighting the need to look at the quality of interagency working and identify strategies for improving collaboration.

\section{Judgement and decision making in organisational systems}

Organisational culture can be described as "a psychosocial process which makes a bridge between individuals' inner worlds and the social institutions in which they live and work" (Taylor et al. 2008 p.24). The culture of the organisation, group and/or team and its norms can influence how we frame decisions (Helm, 2016), how we construct a narrative about a service user and partner agency through a process of 'telling' the story of the case (White and Stancombe, 2003) and can even determine which theories (Smith, 2014) and values (Jaskyte, 2010) are sanctioned to use during any process of analysis.

We have established that relationships between individuals, teams, groups and organisations are dynamic and the levels of influence are non-linear and multi-directional. Organisations provide the procedural and cultural context for the decision making work of the group and the individual. Unfortunately organisational cultures are not always benign. There is a growing recognition that the capacity of social workers to undertake complex and ethically informed decision making has been increasingly undermined by large workloads, a lack of resources, and failures to provide adequate supervision or opportunities to undertake professional development (Preston-Shoot 2011). A range of authors have also identified that managerialist and target-driven cultures have not led to improvements in practice and have in fact undermined the ethical core of the profession (Webb 2006, Emond et al. 2013, Featherstone et al. 2014).

These impacts are undoubtedly significant and it is essential that social workers have an understanding of the potential for 'administrative evil-doing' (Preston-Shoot 2011). Whittaker has argued that "rather than viewing practitioners simply as passive victims caught up in an increasing spiral of overly prescriptive guidance and regulation" we should seek to understand the "complex picture of the way in which practitioners make choices ... it is only in the careful explication of these everyday processes that a deeper understanding can be gained" (Whittaker 2011, p.492). Pathologising and individualising judgement renders the picture incomplete yet there remains the challenge of mapping the territory between the prescribers/regulators and those professionals tasked with making judgements with the system constructed.

Using an ecological model for understanding and engaging with decision making means mapping one's own environmental landscape, being curious about how one's practice is shaped by its context and recognising this context 
as multi-layered. Given the complex ways in which organisational culture, policy and procedure can impact on individuals and groups, where should we begin our reflections? We would assert that a crucial task is to understand the guiding and directing role of core values, an organisation's "essential and enduring tenets" (Collins and Porras, 1994, p.73). The Hackney 'Whole Systems Change' model outlined in the Munro Review places 'shared values' at the heart of the process, suggesting that setting culture and practice in a new direction cannot occur without shared beliefs about what is most important. Preston-Shoot (2011) has also argued practitioners need to be able to reflect critically on the policies and procedures of the organisation and "be able to draw on the legal rules to counter policies and procedures that act against people's best interests" (p.189).

Individual practitioners can use an ecological model to articulate how the organisational and group context is impacting on their decision making practice. Objects have the power to influence our actions and guide our understanding (Miller 2013) and the 'social worker's world' triangle can be used in a variety of ways to support critical reflexivity in practice. For example, practitioners can use the triangle as a visual reminder in the same way that many practitioners already keep laminated copies of the 'child's world' triangle in sight when engaged in assessment. As the 'child's world' triangle helps keep the child in mind throughout assessment, so does the 'social worker's world' triangle ensures that judgements are formed in full consideration of the social worker's ecology of judgement. Educators can use this visual representation of the model to help students reflect, analyse and make explicit those elements of the ecology which influence their judgement, promoting empowerment and facilitating concrete and pragmatic responses to these influencing pressures.

Supervision is a key place where staff could be supported to manage uncertainty and develop reflexivity. Research clearly indicates that many social workers are receiving infrequent and inadequate supervision and that organisations require improved governance to support the provision of effective supervision (BASW 2012).) "If we want safer child protection systems we are going to have to design them for the right species." (Featherstone et al. 2014 p89) and this includes the systems required to support judgement and decision making. This requires a model of judgement that recognises the bounded nature of professional judgement and can foster a learning culture where mistakes are seen as opportunities for growth and learning rather than blame (Munro 2011; Featherstone et al. 2014). Using the ecological model in supervision, review and audit can help to pinpoint and evaluate supports for judgement, including the provision of supervision which promotes critical reflexivity and finely balanced professional judgement.

\section{Discussion and Recommendations for Practice}

Individual judgements are made through repeated interactions with other components of the system (such as colleagues, clients, managers and other professionals) and recent ethnographic research (Ferguson 2011; Helm, 2016; Helm, 2011) has begun to shed light on the vital role that teams play in 
dialogue and the shared process of sense making. The work of authors like Munro (2011) suggests that top-down solutions and cultures of audit and target need to be reconsidered in favour of bottom-up responses that build on the foundations of existing strengths. Following the ecological model of judgement, consideration can be given to the concepts of adaptation and emergence. Working within complex professional systems, social workers will be under pressure to conform but change and instability within these systems can create opportunities for change and the 'emergence' of new ways of thinking and acting. While the ecological model of judgement may not have a prescription for action, it does indicate the importance of emergence, the benefits of close study of practice and the benefits which social workers may gain from simply making sense of their experiences professional judgement. In this respect, the model can provide a framework for disentangling and distinguishing the many different threads of influence that have been spun together to inform judgement.

A further aspect of judgement which the ecological model illuminates is the importance of feedback loops. Munro (2011) used a systems approach to analyse the impact of increased prescription on social work practice, noting the introduction of negative reinforcing loops leading to unintended consequences such as reduced job satisfaction, self-efficacy and ultimately poorer outcomes for service users. A striking feature of many discussions that we have had with practitioners as researchers and educators is the lack of clear and timely feedback on their judgements. Feedback on social worker judgements from the macro-level socio-political sphere is a major, and often negative, influence on individual judgements. While individual practitioner skills and knowledge are currently key elements in the improvement agenda, we would suggest that the benefits of such investments will only be realised if further consideration is given to the links between individual social workers, government and civic society. The different approaches and attitudes to social work practice emerging across the 4 countries of the UK may provide useful data on how the development of such feedback loops will influence practice.

One particularly helpful aspect of a systems approach is the attention that it pays to the organisation and interactions of the constituent parts of the wider system (Price 1997 in Byrne 1998). Research has demonstrated that a range of cognitive biases remain persistent in the face of training and awarenessraising (Tversky and Kahneman 1974 Sheppard 1995, Scott 1998). This indicates that individual practitioner knowledge and skill is insufficient protection against error. A range of organisational precautions against individual error have been developed (such as supervision and independent chairing) but the organisational conditions which can both exacerbate and guard against such errors tend to be overlooked (Broadhurst et al 2010, Bortoli and Dolan 2014). The ecological model makes explicit the interplay between individuals, organisations and wider societal influences on judgements and, by doing so, has the potential to stimulate debate and empower practitioners. The model therefore has utility in team and agency development where the efficacy of such safeguards against bias can be understood holistically and stronger links made between individuals' judgements and macro-level influences. 
Collaboration and respect at all layers of the system are crucial to developing partnerships (Trowler and Goodman, 2012). All members of decision making groups bear responsibility for cultivating an attitude of respect, but those in leadership have a very important role in setting this tone both in formal decision making contexts and in informal decision making fora such as teams and multi-professional networks. Those who chair group decision making meetings have a crucial role in eliciting views and managing difference. Chairs need proper training to be able undertake this complex task (Calder and Horwath 2000; Calder 2003; Prince et al. 2005).

Empirical research into social work decision making practice has been thin on the ground (Helm, 2016; Prince et al. 2005; Taylor, 2006; Taylor et al. 2008) but, increasingly, naturalistic studies are observing social work judgements in the real day-to-day environment of practice. Such methodologies have the potential to shine a light on "how work gets done, rather than how it should be done" (White and Stancombe 2003, p.162 our emphasis added). For researchers engaged in sociological inquiry into social work judgement and decision-making, the ecological model provides a flexible framework for further analysis of complex interactions between the social worker and the wider social and organisational influences on their work.

Developments in the theorizing of decision making have begun to gain momentum with renewed interest in systems theory and ecological models (Baumann et al. 1997; Helm, 2010; Munro 2005). By employing an ecological model of judgement in professional education, social workers are provided with a way of conceptualising the complex system which is an intrinsic part of professional judgement. The ecological model of judgement can facilitate a stronger understanding of the nature of judgement and an enhanced capacity to manage this environment in pursuit of more effective practice.

In summary, we recommend the ecological model to social work educators help students analyse and critically reflect upon influencing and interacting factors in professional judgement. We believe that the ecological model can be used in supervision to promote consideration of the 'missing side of the triangle' and holistic thinking about how judgements are constructed and communicated. Finally, the model can be used in team and agency development to inform plan systems to support judgement which go beyond the individual to encompass a person-in-situation perspective and explicitly address wider influences on judgement.

\section{Conclusions}

Although researchers must grapple with the empirical evidence and understand the existing knowledge base, it is also crucial that they explore the extent to which the concepts and theories they are developing resonate with those whose practice settings they are attempting to illuminate (Orme and Powell, 2007). Munro (2011) has convincingly argued that a dominant organisational culture of procedural compliance is one which is anathema to the development of thinking and transfer of learning. Such an approach fails 
to situate judgment within its wider ecology and therefore fails to address much more than one single part of a complex and interconnected system. A systems analysis of judgement and decision making in child safeguarding can offer insights to inform practice.

Our ecological model supports practitioners to explicitly reflect on the multilayered and interacting factors influencing the way they interpret data and frame judgements. Using an ecological model of judgement creates opportunities to guard against confirmational bias. By moving the focus from the 'facts' under consideration to the factors influencing the judgement, workers are encouraged to think more rigorously about how and why particular interpretations and inferences have been drawn. This model therefore can reduce the potential for positivistic framing of complex issues and can promote the necessary mindset for rigorous doubt and defensible decision making.

Child safeguarding practice has yet to make effective use of this decision making theory and research knowledge to drive practice forward (Baumann et al. 2011) but by mapping and illustrating influencing factors and processes of judgement and decision making, the ecological model can support clearer and more nuanced analysis. The technical-rational model of social worker as rational actor and problem solver ignores the reality that the social worker is actually the problem setter and in making sense of any practice situation, they must skilfully frame the situation in such a way as to both clarify the ends which are to be achieved and how these ends will be achieved. The reflective practitioner requires a model which supports problem setting and does not limit the scope of reflection to the individual technical level. Rigorous use of the ecological model provides the means for the reflector-on-action to frame their work within the broader socio-political sphere and to make explicit the layers of influence on individual judgement and decision-making.

The ecological model describes the way judgements are made in the complexities and uncertainties of social work practice. Modernist, positivistic concepts of judgement may be pervasive but have been challenged in social work education and practice (e.g. Fook 2012). Social workers are therefore increasingly likely to understand judgement as something which is not fixed, singular and logical but as something which is situated, dynamic and subjective; requiring critically reflexive practice. Reframing social work judgement within an ecological perspective therefore promotes critical reflexivity through critical holistic consideration of the practice issues and reflection on the practitioner's own place and influence in the ecology of judgement.

Transactional ecological models are already a familiar tool in assessment and in theorising social work practice. Ecological approaches are fundamental to understanding clients' lived experiences (e.g. DoH 2000, Scottish Executive 2005) and, by applying the model to judgement and decision-making, we hope to promote debate on how current approaches are framed and are influencing practice. We hope that the ecological model may provide a clear and familiar conceptual framework for practitioners to promote critical 
reflexivity in day-to-day practice: supporting explicit consideration of the information environment, prioritising organisational support for judgement and promoting methodical doubt in assessment.

\section{References}

Atkinson, P. (1995) Medical Talk and Medical Work. London, Sage.

Baron, J. (2008) Thinking and Deciding (4th Edition) Cambridge, Cambridge University Press.

Basu, K. (2008) The New Palgrave Dictionary of Economics (2nd Edition) New York, Palgrave Macmillan

BASW (2012) The State of Social Work 2012: What social workers think about the state of their profession in 2012. [online] last accessed 06.06.15 http://cdn.basw.co.uk/upload/basw_23651-3.pdf

Baumann, D., Dalgleish, L., Fluke, J. and Kern, H. (2011) The DecisionMaking Ecology. Washington DC, American Humane Society.

Beckett, C., McKeigue, B. and Taylor, H. (2007) Coming to conclusions: social workers' perceptions of the decision-making process in care proceedings. Child and Family Social Work, 12, 54-63

Broadhurst, K., Wastell, D., White, S., Hall, C., Peckover, S., Thompson, K., Pithouse, A. and Davey, D. (2010) 'Performing "initial assessment": Identifying the latent conditions for error at the front-door of local authority children's services', British Journal of Social Work, 40, pp. 352-70.

Bronfenbrenner, U. (1979). The ecology of human development: Experiments by nature and design. Cambridge, MA, Harvard University Press.

Byrne, D. (1998) Complexity theory and the social sciences: An introduction. Abingdon, Routledge.

Calder, M. (2003) Child Protection Conferences: A framework for chairperson preparation. Child Care in Practice, 9 (1), 32-48.

Calder, M. and Horwath, J. (2000) Challenging passive partnerships in the core group forum: towards a more proactive approach. Child and Family Social Work, 5, 267-277.

Collins, J.C. and Porras, J.I. (1994) Built to last. New York, N.Y., Harper Collins. 
Corby, B., Miller, M. and Young, L. (1996) Parental participation in child protection work: Rethinking the rhetoric. British Journal of Social Work 26, 475-92.

DoH (2000) Framework for the Assessment of Children in Need and their Families. London, The Stationery Office.

Emond, R., Mclntosh, I. and Punch S. (2013) 'Food and feelings in residential child care', British Journal of Social Work. Early online version: doi: 10.1093/bjsw/bct009

Featherstone, B., White, S. and Morris, K. (2014) Reimagining Child Protection: Towards Humane Social Work with Families. Bristol, Policy Press.

Ferguson, H. (2011) Child Protection Practice. Basingstoke, Palgrave Macmillan

Fook, J. (2012) Social Work: A Critical Approach to Practice (2nd Edition). London, Sage.

Forder, A. (1976) Social Work and System Theory. British Journal of Social Work, 6 (1), 23-42

Forkby, T. and Hojer, S. (2011) Navigations between regulations and gut instinct; the unveiling of collective memory in the decision-making processes where teenagers are placed in residential care. Child and Family Social Work, 16, 159-168.

Fish, S., Munro, E., and Bairstow, S. (2008) Learning together to safeguard children: developing a multi-agency systems approach for case reviews. London, SCIE.

Gambrill, E. (2012) Critical Thinking in Clinical Practice: Improving the Quality of Judgements and Decisions. (3rd Edition). New Jersey, Wiley.

Ghaffar, W., Manby, M. and Race, T. (2012) Exploring the Experiences of Parents and Carers whose Children Have Been Subject to Child Projection Plans. British Journal of Social Work (2012) 42 (5), 887 905.doi: 10.1093/bjsw/bcr132

Gigerenzer, G. (2007) Gut Feelings: Short cuts to better decision making. London, Penguin.

Gigerenzer, G, Todd, P. and the ABC Research Group (1999) Simple Heuristics That Make Us Smart. Oxford, Oxford University Press. 
Gillingham, P. and Humphreys, C. (2010) Child Protection Practitioners and Decision-Making Tools: Observations and Reflections from the Front Line. British Journal of Social Work (2010) 40 (8): 2598-2616. doi: 10.1093/bjsw/bcp155

Hall, C. and Slembrouk, S. (2001) Parent participation in social work meetings: the case of child protection meetings. European Journal of Social Work, 4 (2),143-160. ISSN 1369-1457

Hammond, K. (1996) Human Judgement and Social Policy: Irreducible Uncertainty, Inevitable Error, Unavoidable Justice. Oxford, Oxford University Press.

Harlow, E. (2004) Protecting Children: Why Don't Core Groups Work? Lessons from the Literature. Practice, 16, 31- 42.

Harlow, E. and Shardlow, S. (2006) Safeguarding children: challenges to the effective operation of core groups. Child and Family Social Work, 11, 65-72.

Hawthorn, J. and Wilson, P. (2009) Significant Case Review: Brandon Muir. Part 1 Significant Case Review for Dundee Children and Young Person's Protection Committee and Part 2 Independent Inquiry for Chief Officers Group. [online] Last accessed $4^{\text {th }}$ June 2012 at http://www.docstoc.com/docs/20598096/Significant-Case-ReviewBrandon-Lee-Muir\#

Helm, D. (2010) Making Sense of Child and Family Assessment: How to Interpret Children's Needs. Best Practice in Working with Children Series. London: Jessica Kingsley.

Helm, D. (2011) Judgements or Assumptions? The Role of Analysis in Assessing Children and Young People's Needs, British Journal of Social Work, 41 (5), pp. 894-911.

Helm, D. (2016) Sense-making in a Social Work Office: An ethnographic study of safeguarding judgements, Child and Family Social Work, 21 (1), pp. 26-35.

Hitzler, S. and Messmer, H. (2010) Group Decision Making in Child Welfare and the Pursuit of Participation. Qualitative Social Work, 9, 205-226.

Horwath, J. (2006) The Missing Assessment Domain: Personal, Professional and Organizational Factors Influencing Professional Judgements when Identifying and Referring Child Neglect. British Journal of Social Work 37 (8): 1285-1303 [online] last accessed 15.05.15 
Hughes, M. and Wearing, M. (2007) Organisations and Management in Social Work. London, Sage.

Jack, G. and Gill, O. (2003) The missing side of the triangle; assessing the importance of family and environmental factors in the lives of children. Barkingside, Barnardo's

Jaskyte, K. (2010) An Exploratory Examination of Correlates of Organisational Culture. Administration in Social Work, 34, 423-441.

Kahneman, D. (2011) Thinking fast and slow. London, Allen Lane.

Kelly, N. and Milner, J. (1996) Child protection decision making. Child Abuse Review, 5, 91-102.

Kelly, N. and Milner, J. (1999) 'Decision making in case conferences.' In: Children, Child Abuse and Child Protection: Placing Children Centrally. The Violence Against Children Study Group: Chichester, England.

Klein, G. (1998) Sources of Power: How People Make Decisions. Cambridge, Massachusetts, MIT Press.

Laming, H. (2003) The Victoria Climbié Inquiry: Report of an Inquiry by Lord Laming. London, The Stationery Office.

Miller, L. and Fisher, T. (1992) Some obstacles to the effective investigation and registration of children at risk - issues gleaned from a worker's perspective. Journal of Social Work Practice 6, 120-140

Morrison, T. (2005) Staff Supervision in Social Care: Making a real difference for staff and service users ( $\left.3^{\text {rd }} \mathrm{Ed}\right)$. Brighton, Pavilion.

Munro, E. (1999) Common errors of reasoning in child protection. Child Abuse and Neglect, 23 (8), 745 - 758.

Munro, E. (2005) Improving Practice: Child Protection as a Systems Problem. Child and Youth Studies Review, 27 (4), 371-391.

Munro, E. (2008) Effective Child Protection. London, Sage

Munro, E. (2010) The Munro Review of Child Protection. Part one: a systems analysis. London, TSO

Munro, E. (2011) The Munro Review of Child Protection: Final Report - A child-centred system. London, TSO 
Orme, J. and Powell, J. (2007) Building Research Capacity in Social Work: Process and Issues British Journal of Social Work (2008) 38 (5): 9881008

Pincus, A. and Minahan, A. (1973) Social Work Practice: Model and Method. Itasca, III. Peacock.

Preston-Shoot, M. (2011) On administrative evil-doing within social work policy and services: law, ethics and practice. European Journal of Social Work, 14 (2), 177-194.

Prince, J., Gear, A., Jones, C. and Read, M. (2005) The Child Protection Conference: A Study of Process and an Evaluation of the Potential for On-line Group Support. Child Abuse Review, 14, 113-131.

Roesch-Marsh, A. (2011) Better together? Learning lessons for group decision-making practice from a study of secure accommodation in Scotland. Child \& Family Social Work, DOI: 10.1111/j.13652206.2011.00804.x

Roesch-Marsh, A. (2013) Risk Assessment and Secure Accommodation Decision-Making in Scotland: Taking Account of Gender? Child Abuse Review, DOI:10.1002/car.2259.

Scott, D. (1998) A Qualitative Study of Social Work Assessment in Cases of Alleged Child Abuse. British Journal of Social Work, 28, 73-88

Scottish Executive (2005) Getting It Right For Every Child: Proposals for action. Edinburgh, Scottish Executive.

Sheppard, M. (1995) Social work, social science and practice wisdom. British Journal of Social Work, 25, 265-293

Simon, H. (1955) Models of Man: Social and rational; mathematical essays on rational human behaviour in society setting. New York, Wiley.

Simon, H. (1990) Invariants of Human Behaviour. Annual Review of Psychology 41, 1-19

Simon, H. (1990b) 'Alternative visions of rationality' in Rationality in Action: Contemporary Approaches (Moser, P.K., ed.) 189-204, Cambridge University Press

Smith, Y. (2014) Making clinical decision when 'behaviour has meaning'; An ethnographic study of expertise in a residential treatment centre for children and adolescents. Qualitative Social Work, 13, 8-25. 
Stepney, P. and Ford, D. (Eds) (2012) Social Work Models, Methods and Theories: A Framework for Practice. (2nd Edition) Lyme Regis, Russell House

Taylor, B. (2006) Factorial Surveys: Using Vignettes to Study Professional Judgement. British Journal of Social Work, 36 (7), 1187-1207.

Taylor, C. and White, S. (2001) 'Knowledge, truth and reflexivity: The problem of judgement in social work', Journal of Social Work, 1(1), pp. 37-59.

Taylor, H., Beckett, C. and McKeigue, B. (2008) Judgements of Solomon: anxieties and defences of social workers involved in care proceedings. Child and Family Social Work, 13, 23-31.

Thoburn, J., Lewis, A. and Shemmings, D. (1995) Paternalism or partnership? Family involvement in the child protection process. London, HMSO.

Trowler, I. and Goodman, S. (2012) Social Work Reclaimed: Innovative Frameworks for Child and Family Social Work Practice. London, Jessica Kingsley.

Tversky, A. and Kahneman, D. (1974) 'Judgement under uncertainty: Heuristics and biases.' Science, 185, 1124-1131

Van de Luitgaarden, G. (2009) Evidence-Based Practice in Social Work: Lessons from Judgement and Decision-Making Theory. British Journal of Social Work. 39, pp243-260

Webb, S. (2006) Social Work in a Risk Society: Social and political perspectives. Basingstoke, Palgrave Macmillan.

Weber, M. (1978) Economy and Society: An outline of interpretive sociology. Edited by Roth, G and Wittich, C. Berkeley, University of California Press.

White, S. and Featherstone, B. (2005) 'Communicating misunderstandings: Multi agency work as social practice'. Child and Family Social Work, 10(3), 207-216.

White, S. and Stancombe, J. (2003) Clinical Judgment in the Health and Welfare Professions: Extending the Evidence Base. Maidenhead, Open University Press.

Whittaker, A. (2011) Social defences and organisational culture in a local authority child protection setting: challenges for the Munro review?. Journal of Social Work Practice: Psychotherapeutic Approaches in Health, Welfare and the Community, 254 pp481-495 DOI: 10.1080/02650533.2011.626654 


\section{Figure 1}

An ecology of social work judgement 